\title{
Governance issues in business and finance in the wake of the global financial crisis
}

\author{
Sabri Boubaker ${ }^{1,2} \cdot$ Duc Khuong Nguyen ${ }^{3,4}$
}

Published online: 9 May 2017

(C) Springer Science+Business Media New York 2017

The global financial crisis of 2008-2009 has put corporate governance under close scrutiny by politicians, policymakers and the general public. Nowadays, it plays, more than ever before, a critical role in ensuring the well-functioning of the economic system and in maintaining the trust of investors and other key stakeholders in capital markets. There is, not surprisingly, a general consensus among academics and practitioners that the quality of corporate governance depends on a bundle of firm-level governance mechanisms as well as on the quality of the legal, extra-legal and political institutions in the country where the firm operates.

Although studies on corporate governance over the last two decades have brought considerable insights on how corporate governance helps increase the effectiveness of the boards of directors, better understand managerial actions, and regulate the interactions of firms with their environment, many questions are still open to debate and further research is needed to better understand, for example, the various implications that different corporate governance practices have on firm's capital structure, organizational behavior, and managerial actions. This Special Issue of the Journal of Management and Governance aims to draw some lessons from recent studies with international perspectives. It particularly features issues related to executive compensation, ownership structure, market competition, and governance of micro-finance institutions.

Sabri Boubaker

sabri.boubaker@get-mail.fr

$\bowtie$ Duc Khuong Nguyen

duc.nguyen@ipag.fr

1 Champagne School of Management, Troyes, France

2 IRG, Université Paris Est, Créteil, France

3 IPAG Business School, Paris, France

4 Indiana University, Bloomington, IN, USA 
The first paper in this special issue "Does Location Influence Executive Compensation? Evidence from Canadian SMEs" by Harjeet S. Bhabra (John Molson School of Business, Concordia University, Montreal, Canada) and Ashrafee T. Hossain (Memorial University of Newfoundland, St. John's, Canada) analyzes the effect of geographic location on the level and structure of executive compensation of small and medium Canadian enterprises. There is a large body of literature that shows the importance of geographic distance in shaping the costs of monitoring managers. Indeed, the farther the firm is from urban centers, the higher the informational asymmetries and agency problems it faces, which has important implications for corporate policy choices (cost of capital, investment policy, etc.).

In this paper, the authors examine the effect of geographic location on executive compensation policy. This issue is of great importance to small and medium sized enterprises (SMEs) as they are generally located far from urban centers, often suffer from greater information asymmetry and severe manager-shareholder conflicts, and face the challenge of attracting talented and experienced executives. Using a sample 337 Canadian SMEs over the period spanning 2008 to 2011, the authors show that Canadian SMEs tend to design their executive pay packages in a way that attracts high-quality executives and addresses potential information asymmetry and agency problems arising from geographic distance. More precisely, they find that rural SMEs are more likely to pay a large part of the executive compensation in cash in an attempt to attract talented executives. They also find that equity-based pay and payperformance sensitivity are used by rural SMEs as an important tool to align managers' and shareholders' interests. The results, however, show that total compensation remains the same for both urban and rural SMEs.

The second paper "Governance and Performance of MFIs: The Cameroon Case" is by Léopold Djoutsa Wamba (University of Dschang, Cameroon), Isidore Bimeme Bengono (University of Dschang, Cameroon), Jean-Michel Sahut (IDRAC Business School, France and HEG Fribourg, Switzerland) and Frédéric Teulon (IPAG Business School Paris, France). In this study, the authors explore the effect of corporate governance mechanisms on firms' financial and social performance in the context of microfinance institutions (MFIs) in Cameroon. The poor performance of MFIs has raised doubts about the effectiveness of their governance practices which may have an important impact on their decisionmaking and operational processes. Since prior research fails to acknowledge that corporate governance mechanisms can have important positive effects on MFIs performance, the authors of this study examine whether the effectiveness of corporate governance is conditional on the legal status of MFIs. More specifically, they focus on four major governance mechanisms, namely, ownership structure, the characteristics of the board of directors, regulation/supervision, and external auditing. Based on questionnaire data obtained from 137 MFIs' executives in October 2012, the authors show that only 8 out of 20 investigated governance variables matter for MFIs performance. More importantly, they reveal that the effect of governance mechanisms on corporate performance depends on the legal status of the MFI (cooperative and mutual benefit companies, non-profit NGOs, and private companies and profit seeking NGOs). This result suggests that the 
implementation of corporate governance practices should be adapted to the legal status of the MFI to make it more effective in improving corporate performance.

The third paper in this special issue "Product Market Competition and Analyst Following” by Syrine Sassi (IRG, Université Paris Est Créteil, France) and Narjess Toumi (IRG, Université Paris Est Créteil, France) analyzes the effect of product market competition on the extent of analyst coverage of French listed firms. The vast body of academic research on financial analysts has paid relatively little attention to the question of whether industry characteristics have any influence on analyst following. Since previous studies document that analyst activity may significantly differ across industries (e.g., Bhushan 1989; O’Brien and Bhushan 1990; Boubaker and Labégorre 2008), the authors aim in their paper is to further our understanding of the underlying industry factors that account for these differences. More specifically, their study examines the link between product market competition and analyst following. On the one hand, product market competition has been shown to impinge on firms' information environments by discouraging the revelation of private information to rivals, which increases investors' need to information provided by financial analysts. On the other hand, it is widely documented that competition acts as an external disciplinary mechanism by exposing firms to severe liquidation threats, which might in turn substitute for analyst screening and monitoring services.

To empirically examine these two competing arguments, the authors use a sample of 520 French listed firms from 2000 to 2013. After controlling for various determinants of analyst following, the findings lend strong support to the substitution effect argument by showing that the number of analysts following a given listed firm decreases with the intensification of product market competition. These results suggest that the disciplinary power of competition is effective in reducing the marginal benefit of analyst coverage that provides similar disciplinary effects. In other words, product market competition makes shareholders more confident that firms are well monitored, which provides less incentives for investors to seek more private information from financial analysts. The authors conclude that there is a substitution effect between competition and analyst following as an external corporate governance mechanism.

Finally, in the paper "Ownership Structure and Investment-cash Flow Sensitivity" by Imen Derouiche (University of Luxembourg, Luxembourg), Majdi Hassan (DEFI, ESSEC Tunis, Tunisia) and Amdouni Sarra (DEFI, ESSEC Tunis, Tunisia), the authors study the effect of control-ownership wedge on the sensitivity of investment to cash flows. Consistent with the free cash flow hypothesis of Jensen (1986), self-interested insiders may use abundant internal funds at their disposal to undertake unprofitable and unnecessary investments-overinvestment-, especially when profitable projects are scarce. In this context, the extent to which investment is sensitive to cash flow may depend on the severity of agency problems arising from the tendency of insiders to obtain pecuniary and non-pecuniary private benefits by overinvesting. In this study, the authors examine this issue by focusing on the effect of agency problems associated with ownership structure on investment-cash flow sensitivity of firms with concentrated ownership. 
Building on the premise that agency costs are lower when controlling shareholders' wealth is more closely tied to the firm (e.g., Jensen and Meckling 1976), the authors hypothesize that overinvestment, and thereby positive investment-cash flow sensitivity, decreases with cash-flow rights of controlling shareholders. Moreover, based on the evidence that controlling shareholders are more likely to entrench themselves and to pursue private benefits when their control rights exceed cash-flow rights (e.g., Claessens et al. 2002; Boubaker et al. 2014; Ben-Nasr et al. 2015), they predict that overinvestment, reflected in the positive investmentcash flow sensitivity, increases with controlling shareholders' excess control rights. Using a sample of 6797 French listed firms from 2000 to 2013, the authors show that controlling shareholders' cash-flow rights negatively affect investment cash-flow sensitivity, supporting that dominant shareholders are less likely to engage in overinvestment when their interests are aligned with those of minority shareholders. Moreover, they find that the excess control rights of the controlling shareholders have a positive effect on this sensitivity, which confirms that the entrenchment effect associated with separation of control and ownership increases the controlling shareholders' likelihood to overinvest so as to facilitate the extraction of private benefits. Overall, this last paper provides further insights into the prominent role of agency problems between controlling and minority shareholders in shaping the financial policy of firms with concentrated control.

We were very pleased to act as guest-editors for this special issue that stays on the cutting edge of several important and challenging topics in corporate governance. Insights from the selected papers would favour new research. Last but not least, we would like to thank the Editor-in-Chief, Professor Lino Cinquini, and the former Editor-in-Chief, Professor Roberto Di Pietra, for providing us with invaluable guidance during the reviewing and editorial process of this special issue. We are also very grateful to the anonymous reviewers for their rigorous reviewing reports.

\section{References}

Ben-Nasr, H., Boubaker, S., \& Rouatbi, W. (2015). Ownership structure, control contestability and corporate debt maturity. Journal of Corporate Finance, 35, 265-285.

Bhushan, R. (1989). Firm characteristics and analyst following. Journal of Accounting and Economics, 11, 255-274.

Boubaker, S., Cellier, A., \& Rouatbi, W. (2014). The sources of shareholder wealth gains from going private transactions: The role of controlling shareholders». Journal of Banking \& Finance, 43, $226-246$.

Boubaker, S., \& Labégorre, F. (2008). Ownership structure, corporate governance and analyst following: A study of French listed firms. Journal of Banking \& Finance, 32, 961-976.

Claessens, S., Djankov, S., Fan, J. P. H., \& Lang, L. H. P. (2002). Disentangling the incentive and entrenchment effects of large shareholdings. Journal of Finance, 57, 2741-2771.

Jensen, M. C. (1986). Agency cost of free cash flow, corporate finance, and takeovers. American Economic Review, 76, 323-329.

Jensen, M., \& Meckling, W. (1976). The theory of firm: Managerial behavior, agency costs and ownership structure. Journal of Financial Economics, 3, 305-350. 
O’Brien, P. C., \& Bhushan, R. (1990). Analyst following and institutional ownership. Journal of Accounting Research, 28, 55-76.

Sabri Boubaker is a Professor of Finance at Champagne School of Management (Groupe ESC Troyes en Champagne, France) and Research Fellow at the Institut de Recherche en Gestion (University of Paris Est). He holds a Ph.D. in Finance from University of Paris Est (2006) and a HDR degree (Habilitation for Supervising Doctoral Research) in 2010 from the same university. He has published many academic papers in international refereed journals such as Journal of Corporate Finance, Journal of Banking and Finance and Financial Management.

Duc Khuong Nguyen is Professor of Finance and Deputy Director for Research at IPAG Business School, France. He holds a Ph.D. in Finance from the University of Grenoble Alpes and a HDR (Habilitation for Supervising Scientific Research) degree in Management Science from University of Cergy-Pontoise, and completed an executive education program in "Leadership in Development" at Harvard Kennedy School. He is also a Non-Resident Research Fellow at the School of Public and Environmental Affairs, Indiana University. 